\title{
Ontogeny of critical swimming speed of wild-caught and laboratory-reared red drum Sciaenops ocellatus larvae
}

\author{
Ana M. Fariaa, ${ }^{1,}$, Alfredo F. Ojanguren ${ }^{3}$, Lee A. Fuiman ${ }^{3}$, Emanuel J. Gonçalves ${ }^{1, *}$ \\ ${ }^{1}$ Eco-Ethology Research Unit, Instituto Superior de Psicologia Aplicada, R. Jardim do Tabaco 34, 1149-041 Lisbon, Portugal \\ ${ }^{2}$ Centre of Marine Sciences, CCMAR, University of Algarve. Campus de Gambelas, 8005-139 Faro, Portugal \\ ${ }^{3}$ Marine Science Institute at Austin, University of Texas, 750 Channel View Drive, Port Aransas, Texas 78373, USA
}

\begin{abstract}
Critical swimming speed $\left(U_{\text {crit }}\right)$ provides a useful estimate of maximum swimming performance for fish larvae that can be used to assess transport and migratory potential. We measured $U_{\text {crit }}$ of red drum Sciaenops ocellatus larvae through its ontogeny and compared the swimming performance of laboratory-reared larvae to that of wild-caught individuals. $U_{\text {crit }}$ increased with ontogeny (size), even though variability in $U_{\text {crit }}$ at any ontogenetic state was large. $U_{\text {crit }}$ for wild-caught larvae increased from 9.7 to $22.2 \mathrm{~cm} \mathrm{~s}^{-1}$ over the range of 8.3 to $16.3 \mathrm{~mm}$ TL and from 1.1 to $20.5 \mathrm{~cm} \mathrm{~s}^{-1}$ over the range of 3.0 to $19.1 \mathrm{~mm}$ TL for reared larvae. The ontogenetic increase in critical swimming speed occurred in 2 phases - an early phase of rapid improvement and a later phase of slower improvement. This sharp change in the trajectory of swimming performance coincided with important changes in ecology, morphology, and hydrodynamics. During the early phase, larvae were pelagic, their growth was highly allometric, especially in the caudal region, and they swam in the inertial hydrodynamic regime. The onset of the later phase coincided with settlement into seagrass beds, isometric growth, and inertial effects on locomotion. Wild larvae generally exhibited greater values of $U_{\text {crit }}$ than reared larvae of a comparable size, but the difference was not statistically significant. The results of this comparison imply that research on reared larvae may provide naturalistic results for swimming performance and that hatchery-produced larvae may perform certain behaviours well when released into the wild.
\end{abstract}

KEY WORDS: Scaling · Ontogeny · Swimming performance $\cdot$ Settlement $\cdot$ Hydrodynamics $\cdot$ Wild larvae $\cdot$ Reared larvae

Resale or republication not permitted without written consent of the publisher

\section{INTRODUCTION}

Studies on the behavioural abilities of late-stage pelagic larvae have shown that some species are unexpectedly strong swimmers and have high endurance (Stobutzki \& Bellwood 1994, Leis \& Carson-Ewart 1997). As they approach settlement stage, larvae of many fish become 'effective' swimmers (sensu Leis \& Stobutzki 1999), meaning that they are able to swim faster than mean ambient current speeds (Stobutzki \& Bellwood 1994, Leis \& Carson-Ewart 1997, 2003, Fisher et al. 2000, Jenkins \& Welsford 2002, Trnski 2002). These abilities have the potential to influence survival by affecting the capacity of larvae to avoid predators, find food, and control dispersal (Stobutzki \& Bellwood 1994, 1997).

Studying behavioural ontogeny requires sampling larvae representing a wide variety of ontogenetic stages (sizes). Late-stage larvae of some species are easily captured in good condition using light traps (Doherty 1987) or fixed nets (Dufour \& Galzin 1993). Usually, younger larvae can only be captured using plankton nets and are more susceptible to injury or death in the process (Leis et al. 2006a). For that reason, studies of younger larvae have focused on species that can be reared in captivity (Leis et al. 2006a). An obvious and 
important question is whether the behaviour, or specifically swimming performance, of reared larvae is similar to that of wild larvae. From the available data, the answers are mixed. It is generally agreed that behaviours with a learned component, such as anti-predator behaviour, will differ between wild and reared individuals because larvae from the 2 sources have very different experiences (Olla et al. 1998, Brown \& Laland 2001). However, some tested behaviours present contradictory results. For example, reared fish may swim faster, slower, or they may have performances equivalent to wild fish, with ontogenetic variations further complicating this picture (von Westernhagen \& Rosenthal 1979, Danilowicz 1996, Smith \& Fuiman 2004). The same is true for other behaviours. So, when using results from reared individuals, it is desirable to compare the behaviour of these larvae to that of wild fish, especially if the results will be used to make inferences about fish in nature (Leis 2006).

Some fishes that breed in coastal marine waters use estuaries as nursery habitat for their late-stage larvae and juveniles. To enter an estuary, larvae may rely on passive transport (Jenkins et al. 1997, 1999) or some form of active behaviour, such as selective tidal stream transport (Forward et al. 1998, 1999) or active swimming (Trnski 2002, Leis \& Carson-Ewart 2003). Once in the estuary, high levels of swimming performance may be required both to prevent larvae from being advected out of the estuary and to find and settle in a suitable habitat (Montgomery et al. 2001).

Red drum Sciaenops ocellatus is an estuarine-dependent species that supports an important recreational fishery throughout the Gulf of Mexico and the southeastern United States. Red drum spawns during early autumn in coastal waters near passes and inlets where the pelagic eggs and larvae are carried by tides and currents into shallow bays and estuaries (Holt et al. 1989). After tidal transport into estuaries and initial settlement in habitats near inlets (at ca. 6 to $8 \mathrm{~mm}$ ), juvenile red drum are thought to disperse throughout the estuary, with documented movements into shallow tidal creeks and lower salinity habitats (Peters \& McMichael 1987, Stunz et al. 2002). Such dispersal can be passive (Jenkins et al. 1997, 1999) or an active behavioural response (Leis et al. 1996, Stobutzki \& Bellwood 1997).

Critical swimming speed $\left(U_{\text {crit }}\right)$ provides a useful estimate of maximum swimming performance of fish larvae (Plaut 2001, Fisher 2005). Although it is a measure of prolonged swimming speed that is rarely, if ever, experienced by fishes in nature (Plaut 2001), it provides a useful measure for comparing taxa or developmental states (Leis 2006). Work on $U_{\text {crit }}$ in fish larvae has concentrated on late-stage larvae of coral reef fishes, nearing settlement (e.g. Stobutzki \& Bellwood
1997, Fisher \& Bellwood 2002, Fisher \& Wilson 2004, Fisher et al. 2005). However, to determine the potential importance of swimming behaviour, it is essential to know how these abilities change during ontogeny. Relatively few measures of swimming performance are available for larvae smaller than those at settlement stage, but there are a few recent studies that focus on that issue (e.g. Fisher et al. 2000, Clark et al. 2005, Leis et al. 2006a,b, 2007, Guan et al. 2008).

The goals of our study were to describe the ontogenetic changes in swimming ability (defined as $U_{\text {crit }}$ ) of a warm temperate perciform species, Sciaenops ocellatus, and to compare swimming performance of wildcaught and reared larvae.

\section{MATERIALS AND METHODS}

Larvae. Red drum Sciaenops ocellatus eggs were obtained from captive broodstock at the University of Texas Marine Science Institute's Fisheries and Mariculture Laboratory. Spawning was achieved without hormone injections by manipulating temperature and photoperiod. Eggs were collected within 10 h of spawning, placed into conical rearing tanks with approximately 401 of filtered seawater and aeration, and were left to hatch. Temperature and salinity were maintained at 25 to $27^{\circ} \mathrm{C}$ and 27 to $30 \mathrm{PSU}$, respectively. Rotifers Brachionus sp. were enriched with algae Schizochytrium sp. (Algamac-2000, Aqua-fauna Bio-Marine) for $45 \mathrm{~min}$ and were then added to culture tanks daily to maintain densities of 5 to 10 rotifers $\mathrm{ml}^{-1}$ from Day 1 to 12 posthatching. When larvae were $10 \mathrm{~d}$ old, brine shrimp Artemia sp. nauplii, enriched overnight, were also added daily to culture tanks at densities of $10 \mathrm{ml}^{-1}$. In conjunction with this diet shift, tank volume was increased to $50 \mathrm{l}$. Ten percent of the total volume of water was exchanged daily in each tank. Throughout rearing and experimentation, larvae were maintained on a 12:12 h light:dark photoperiod. Tested larvae were randomly selected from 6 separate spawns that occurred between 10 September and 11 October 2007.

Wild red drum larvae were collected from seagrass meadows in the Aransas Bay, mostly from the southern end of the Lydia Ann Channel, near Port Aransas, Texas, (275 $\left.54^{\prime} 50.63^{\prime \prime} \mathrm{N}, 97^{\circ} 2^{\prime} 41.63^{\prime \prime} \mathrm{W}\right)$ between 25 September and 16 October 2007 (5 collections, $1 \mathrm{wk}^{-1}$ ). At collection sites, temperatures and salinities ranged from 27 to $29^{\circ} \mathrm{C}$ and from 16 to 24 PSU, respectively. Newly settled larvae (size range: 8.3 to $16.3 \mathrm{~mm}$ total length [TL]) were collected using a $1 \mathrm{~mm}$ mesh plankton net towed behind a benthic sled. The rectangular opening of the net measured $1 \mathrm{~m}$ (width) $\times 0.25 \mathrm{~m}$ (height), and was towed slowly by hand to avoid damaging larvae. Collected larvae were placed in a bucket 
of ambient seawater with aeration and transported to the laboratory. Wild larvae were then placed in plastic tanks with artificial seagrass to reduce stress and filled with filtered seawater maintained at a mean $( \pm \mathrm{SD})$ temperature and salinity of $27.2 \pm 0.3^{\circ} \mathrm{C}$ and $26.7 \pm$ 1.4 PSU. Larvae were fed Artemia sp. nauplii and allowed to acclimate in the laboratory for approximately $48 \mathrm{~h}$, by which time they readily consumed the Artemia sp. provided.

Swimming chamber. The swimming chamber was used following the protocols of Stobutzki \& Bellwood (1994, 1997). The chamber was made of clear Perspex with 6 parallel swimming lanes, each $30 \mathrm{~mm}$ wide, $50 \mathrm{~mm}$ high and $180 \mathrm{~mm}$ long. A removable lid allowed introduction and removal of fish from the lanes. A strip of black tape on the top of the lid provided fish with a visual reference to maintain position in the flow, and a mesh screen was placed at the upstream and downstream ends of each lane to retain larvae. A section of flow straighteners, $40 \mathrm{~mm}$ long, was placed at the upstream end of each lane to minimize turbulence. Previous work demonstrated that, at the typical $U_{\text {crit }}$ water velocity was not significantly different between the centre of the lane and $5 \mathrm{~mm}$ from the wall (Stobutzki \& Bellwood 1997, Stobutzki 1998, Fisher et al. 2000). Experimental observations also confirmed that larvae did not show depth preference in the chamber.

The swimming chamber was part of a closed system of water flow. A submersible pump (Ecovort 510, $330 \mathrm{~W}$ ) moved water from a collecting tank located $65 \mathrm{~cm}$ below the swimming chamber. Water flowed out of the swimming chamber and into the collecting tank. A ball valve at the upstream end of the swimming chamber was used to control water velocity. A protractor was mounted on the valve handle, and the angle of the handle was calibrated to flow rates in the swimming lanes by recording the time taken for the outlet water to fill a 51 container and dividing by the crosssectional area and number of lanes. The average of 3 calibrations was used as the flow speed for a specific valve angle. A calibration curve was established at the start of the experiment, with the angle as the predictor and the water velocity as the dependent variable. This curve allowed us to determine the angles required to set velocities during the trials. Experiments were conducted using flow speeds in the lanes ranging from 1 to $22 \mathrm{~cm} \mathrm{~s}^{-1}$.

Experimental protocol. Experiments with reared fish were performed throughout the larval period (over the size and age range of 2.8 to $19.1 \mathrm{~mm}$ TL and 9 to $31 \mathrm{~d}$ post-hatching [dph], respectively). Larvae reared from 6 spawns were used so that batch effects could be tested. In the morning of each experimental day, 6 to 12 fish were tested. Between 1 and 2 h after feeding, larvae were carefully removed from the rearing tank using a small container and placed individually in large glass bowls with approximately 11 of seawater and left undisturbed for $2 \mathrm{~h}$ to allow recovery from handling (Fuiman \& Ottey 1993). For wild fish, 12 to 18 individuals from each collecting day were tested. Wild larvae were placed individually in the large glass bowls during the night and left undisturbed in a controlled temperature room for testing the next morning.

Six fish were transferred from the glass bowls to the swimming chamber, 1 in each lane, and allowed to acclimate for $5 \mathrm{~min}$ at a flow speed of $1 \mathrm{~cm} \mathrm{~s}^{-1}$. If any behavioural symptoms of stress, such as lying on the bottom or clinging to the sides, were observed after this acclimation period, the individual was removed and replaced by another fish. Water temperatures in the chamber over the study period varied from 24 to $26^{\circ} \mathrm{C}$.

To measure $U_{\text {crit, }}$ water velocity was increased by approximately $1.5 \mathrm{~cm} \mathrm{~s}^{-1}$ every 2 min until the larva was unable to swim against the current for $2 \mathrm{~min}$. Calculation of $U_{\text {crit }}$ followed Brett (1964):

$$
U_{\text {crit }}=U+\left(t / t_{\mathrm{i}} \times U_{\mathrm{i}}\right)
$$

where $U$ is the highest speed a fish was able to maintain, $U_{\mathrm{i}}$ is the velocity increment, $t$ is the time swum in the final velocity increment, and $t_{\mathrm{i}}$ is the time interval for each velocity increment (2 min). After the test, fish were euthanized by thermal shock and immediately photographed under a dissecting microscope. Notes on ontogenetic progress were made, and TL was measured to the nearest $0.01 \mathrm{~mm}$, using Image J software (Version 1.38).

Data analysis. Six spawns of reared larvae and 5 collections of wild larvae yielded measurements of $U_{\text {crit }}$ from 338 and 87 larvae, respectively. The relationship between $U_{\text {crit }}$ and TL was examined for each group of wild and reared larvae by analysing scatterplots and computing linear regressions of $\log U_{\text {crit }}$ against $\log \mathrm{TL}$, described by the equation:

$$
\log U_{\text {crit }}=a+b \times(\log \mathrm{TL})
$$

where $a$ and $b$ are constants. All data were $\log _{10}$ transformed to homogenize variances and normalize the data. Relationships between $\log U_{\text {crit }}$ and age were also investigated for reared larvae for which age was known.

Totals of 23 wild larvae and 9 reared larvae were able to swim at the highest speed that could be achieved in the chamber $\left(22.2 \mathrm{~cm} \mathrm{~s}^{-1}\right)$ and could not be fatigued by the experimental protocol. Therefore, the actual critical swimming speed of these individuals was $>22.2 \mathrm{~cm} \mathrm{~s}^{-1}$. As the percentage of wild larvae that could not be fatigued was appreciable (26\%), Tobit regression models (Tobin 1958, Amemiya 1984) were used to obtain realistic slopes and intercepts for the relationships between $\log U_{\text {crit }}$ and $\log$ TL. The Tobit 
model is a modified linear regression, very efficient for estimating the relationship between an explanatory variable and a truncated or censored dependent variable. This procedure accounted for right-censored data, i.e. individuals that were still swimming at the maximum speed that the swimming chamber could produce. Since ANCOVA does not take into account censored data, the $95 \%$ confidence intervals (CI) for the estimated slopes and intercepts ( $a$ and $b$, derived from the Tobit regression) were used to test for differences between batches of domestic fish and between capture dates and cohorts of wild-caught larvae, and to compare swimming performance between wild and reared larvae. For this latter analysis, we only considered reared larvae larger than the smallest fish collected from the wild. A chi-squared model was used to evaluate the significance of the relationship between $\log U_{\text {crit }}$ and $\log$ TL. For non-censored data (Batches 1, $3,4,5$ and 6 of reared fish), the ordinary least-squares model was used.

The linear regression of $\log U_{\text {crit }}$ on $\log \mathrm{TL}$, for reared larvae, yielded a trend in the residuals, indicating that the log-linear model was not appropriate for those data. Thus, a piecewise regression model was used in the form:

$\log U_{\text {crit }}=a+b \times \log \mathrm{TL}+c \times(\log \mathrm{TL}-d) \times(\log \mathrm{TL}>d)$

where $a$ is the intercept for the lower piece, $b$ is the slope of the lower piece, $c$ is the change in slope for the upper piece, and $d$ is the breakpoint between the 2 pieces of the regression. The final term in the equation is a logical statement and takes on a value of 1 if true and 0 if false. If the $95 \% \mathrm{CI}$ for parameter $c$ includes 0 , the piecewise model is rejected in favour of a linear model (Eq. 1).

Using morphometric data for red drum (L. A. Fuiman unpubl.), it was possible to explore the relation between changes in body shape and swimming capacity, particularly before and after the breakpoint determined by the piecewise regression model. A growth gradient for red drum larvae was constructed using the methods of Fuiman (1983), to identify the degree of differential growth in different parts of the body. This method uses the allometric equation:

$$
y=b \times x^{k}
$$

where $b$ is a constant, $k$ is the growth coefficient, $y$ is the length of a body section, and $x$ is a standard that represents size. In this case, eye diameter was chosen as the standard for size because it is a distinct organ that usually grows at a constant differential rate with respect to total length (i.e. it displays a single growth stanza; Fuiman 1983). Measurements of body sections were made parallel to the longitudinal axis of the fish, from the tip of the snout to a vertical line through each designated landmark (Fig. 1). Lengths of body sections were measured on a developmental series of specimens. The growth coefficient $(k)$ and its variability for each segment were determined as the slope and its $95 \% \mathrm{CI}$ in the regression of log-transformed data. The location of the body segment midpoint, the independent variable of the growth profile, was estimated by its mean position from the tip of the snout, as a percentage of TL.

Changes in body size will also influence swimming speed by placing larvae in different hydrodynamic regimes. The Reynolds number $(\mathrm{Re})$ is the index commonly used to characterize hydrodynamic conditions and is calculated from the length and speed of a swimming organism and the kinematic viscosity of the surrounding fluid (Webb \& Weihs 1986). Re was calculated to determine whether larvae were swimming at speeds where either viscous ( $R e<600$ for red drum larvae) or inertial forces $(\operatorname{Re}>1300)$ predominate (Sarkisian 2005).

Statistical tests were conducted using SPSS (Version 16.0) and Stata (Version 10.0).

\section{RESULTS}

A total of 338 reared larvae of Sciaenops ocellatus from 6 spawns and 87 wild larvae of the same species from 5 weekly collections were tested. Of these, 23 wild larvae and 9 reared larvae could not be fatigued (i.e. $U_{\text {crit }}$ was $>22.2 \mathrm{~cm} \mathrm{~s}^{-1}$ ). Swimming performance $\left(U_{\text {crit }}\right)$ increased with ontogeny (logTL), even though variation was large within the range of sizes tested (Fig. 2). Critical speeds for wild larvae ranged from 9.7 to $22.2 \mathrm{~cm} \mathrm{~s}^{-1}$ over the size range of 8.3 to $16.3 \mathrm{~mm} \mathrm{TL}$. This corresponds to length-specific speeds of approximately 9 to 21 body lengths (BL) $\mathrm{s}^{-1}$. Swimming performance of reared larvae ranged from 1.1 to $20.5 \mathrm{~cm} \mathrm{~s}^{-1}$ over the range of 3.0 to $19.1 \mathrm{~mm} \mathrm{TL}$, corresponding to 3 to $20 \mathrm{BL} \mathrm{s}^{-1}$ (Table 1). For reared larvae, age was a poorer predictor of $U_{\text {crit }}$ than size. Although all spawns showed a significant relationship between $\log U_{\text {crit }}$ and

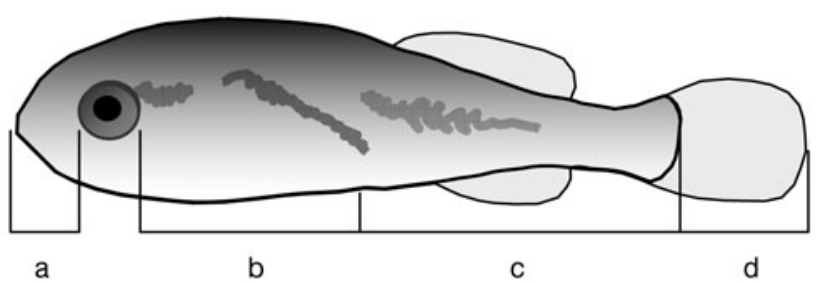

Fig. 1. Sciaenops ocellatus. Measurements of body sections of the larvae. a: snout length; b: pre-anal length, excluding the snout and the eye; c: post-anal length, excluding caudal fin; d: caudal fin length 


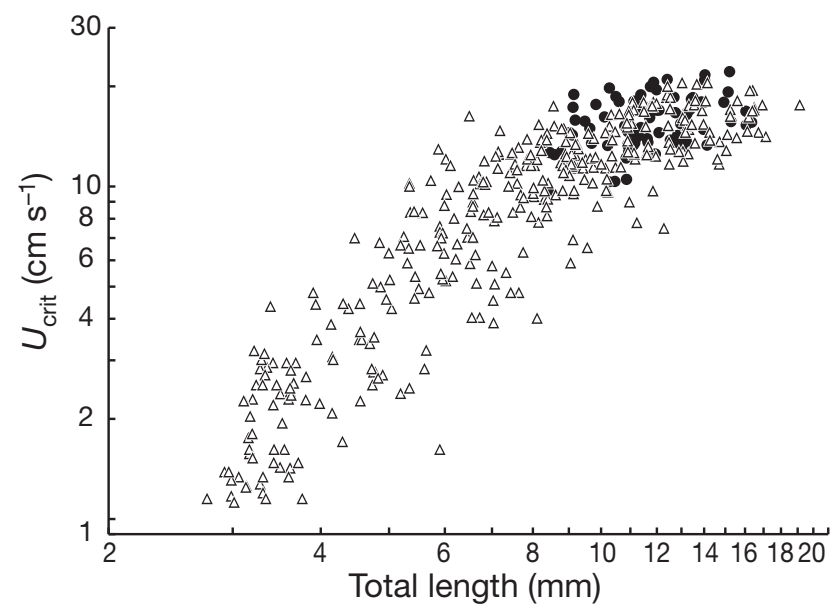

Fig. 2. Sciaenops ocellatus. Ontogenetic trend for critical swimming speed of red drum. Each symbol represents results for an individual larva. $\Delta$ : laboratory-reared larvae; •: wild-caught larvae

age, age explained less of the variation in $\log U_{\text {crit }}$ than $\log$ TL in 5 of the 6 spawns.

Although wild larvae seemed to have slightly better swimming performance (Fig. 3), Tobit regression showed that there was no difference between trends for wild and reared larvae. Comparisons of the $95 \% \mathrm{CI}$ revealed no significant differences in slopes or in intercepts of the 2 regression models (Table 2).

Tobit regression showed significant relationships between $\log U_{\text {crit }}$ and $\log$ TL for wild Cohorts 2, 3 and 5, but no significant relationship for Cohorts 1 and 4 . Comparisons of the $95 \%$ CI showed no significant differences in the slopes or the intercepts of the models (Table 2).

Regarding reared larvae, Tobit regression analyses showed that the slopes differed between some of the batches (Table 2). This is a result of the different size ranges: batches that included only relatively large larvae had smaller slopes than batches that included

Table 1. Sciaenops ocellatus. Summary of measurements of swimming performance for wild-caught red drum larvae (all collections combined) and 6 batches (B1 to B6) of red drum larvae reared from captive spawned broodstock. BL: body length; TL: total length; dph: days post-hatching; SD: standard deviation; nd: data not available

\begin{tabular}{|c|c|c|c|c|c|c|c|}
\hline & \multirow[t]{2}{*}{$\mathrm{N}$} & \multirow[t]{2}{*}{$\mathrm{TL}(\mathrm{mm})$} & \multirow{2}{*}{$\begin{array}{l}\text { Age } \\
\text { (dph) }\end{array}$} & \multicolumn{2}{|c|}{$-U_{\text {crit }}\left(\mathrm{cm} \mathrm{s}^{-1}\right)-$} & \multicolumn{2}{|c|}{$-U_{\text {crit }}\left(\mathrm{BL} \mathrm{s}^{-1}\right)-$} \\
\hline & & & & Range & Mean \pm SD & Range & Mean \pm SD \\
\hline $\begin{array}{l}\text { Wild } \\
\text { larvae }\end{array}$ & $e^{87}$ & $8.3-$ & nd & $9.7-22.2$ & $15.7 \pm 2.7$ & $9.4-20.7$ & $13.6 \pm 2.45$ \\
\hline B1 & 26 & $10.2-15.3$ & $20-24$ & $7.5-20.5$ & $16.0 \pm 3.3$ & $6.1-16.2$ & $12.8 \pm 2.6$ \\
\hline B2 & 92 & $5.9-19.1$ & $17-31$ & $1.6-19.5$ & $11.7 \pm 3.8$ & $2.7-25.1$ & $11.6 \pm 3.6$ \\
\hline B3 & 115 & $2.8-14.2$ & $9-27$ & $1.1-20.5$ & $8.6 \pm 5.13$ & $3.1-20.4$ & $11.2 \pm 4.6$ \\
\hline B4 & 36 & $3.9-13.4$ & $12-17$ & $4.4-20.0$ & 10.0 & $6.5-17.7$ & $11.6 \pm 3.3$ \\
\hline B5 & 40 & 3 & $10-14$ & $1.5-11.6$ & 4.2 & $4.3-18.9$ & $9.2 \pm 3.6$ \\
\hline B6 & 29 & $3.0-6.6$ & $10-13$ & $1.3-9.5$ & $4.0 \pm 2.1$ & $3.7-15.7$ & $8.4 \pm 3.1$ \\
\hline
\end{tabular}

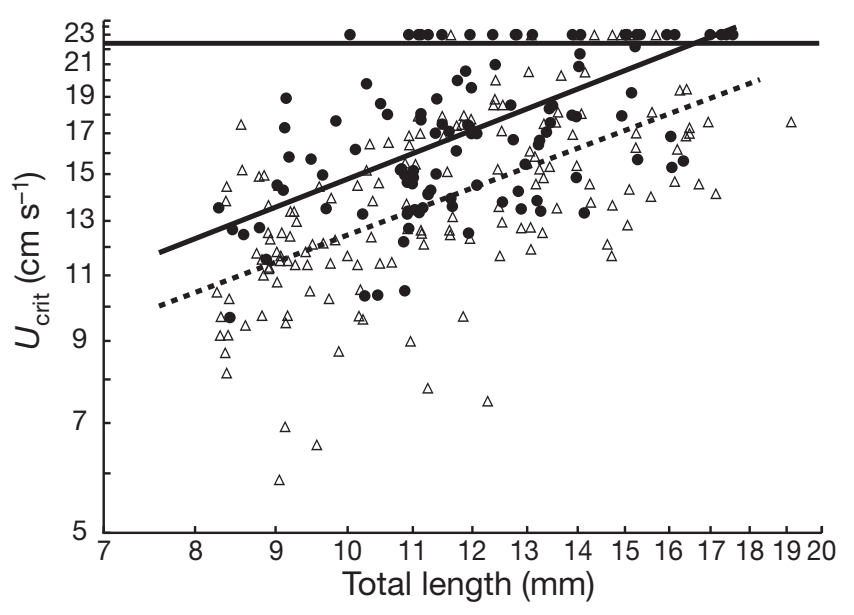

Fig. 3. Sciaenops ocellatus. Relationship between critical swimming speed $\left(U_{\text {crit }}\right)$ and total length for wild-caught and laboratory-reared red drum larvae over a common size range. Continuous line: regression for wild larvae; broken line: regression for reared larvae. Regression lines were obtained using Tobit regression models. $\Delta$ : laboratory-reared larvae; $\bullet$ : wild-caught larvae. Symbols above the horizontal continuous line represent individuals that could not be fatigued, i.e. $U_{\text {crit }}>22.2 \mathrm{~cm} \mathrm{~s}^{-1}$

smaller larvae. This suggests a non-linear relationship between $\log U_{\text {crit }}$ and $\log \mathrm{TL}$ when considering a wide range of larval sizes or ontogenetic states.

Data for reared larvae covered a broader range of sizes and showed a clear picture of the ontogenetic change in $U_{\text {crit }}$. The parameter estimates for the piecewise regression were $a=-0.83, b=2.14, c=-1.36$ $(95 \% \mathrm{CI}=-1.61$ to -1.10$)$ and $d=0.84(95 \% \mathrm{CI}=0.80$ to 0.87 ). Thus, the piecewise regression confirms the existence of a breakpoint in the relationship at $\log \mathrm{TL}=$ 0.84. This breakpoint corresponds to $6.9 \mathrm{~mm}$ TL (6.2 to $7.5 \mathrm{~mm} \mathrm{TL}$ ) (Fig. 4). To determine whether the slope of the upper branch of the piecewise regression would have been higher if considering the larvae that never fatigued, a Tobit regression model was applied for fish larger than at the breakpoint $(6.9 \mathrm{~mm}$ TL), including the 9 larvae that did not fatigue. The resulting slope was 0.89 (95\% CI: 0.74 to 1.04 ), which was not significantly different from the slope estimated by the piecewise model (0.78).

The growth profile for larvae smaller than those at the breakpoint $(6.9 \mathrm{~mm}$ TL) showed a clear U-shaped pattern, meaning that the snout and caudal fin grew faster (relative to eye diameter) than the central body sections. Growth profiles for larvae larger than those at the breakpoint lacked the U-shaped pattern (Fig. 5). 
Table 2. Sciaenops ocellatus. (A) Results of the Tobit regression model $\left(\log _{10} U_{\text {crit }}=a \times \log _{10} \mathrm{TL}+b\right)$ performed on censored data and test of the relationship between $\log U_{\text {crit }}$ and $\log$ TL for wild-caught red drum larvae (all collections combined and each separate cohort) and reared red drum larvae (all larvae and Batch 2, because this was the only batch with censored data). (B) Results of the least-squares model performed on non-censored data and test of the relationship between $\log U_{\text {crit }}$ and $\log$ TL for each separate batch of reared larvae (Batches 1, 3, 4, 5 and 6). a: slope; $b$ : intercept; corr.: correlation (A: $\chi^{2} ; \mathrm{B}: \mathrm{R}^{2}$ )

\begin{tabular}{|c|c|c|c|c|c|c|c|}
\hline & a & $95 \% \mathrm{CI}$ & $b$ & $95 \% \mathrm{CI}$ & $\mathrm{n}$ & Corr. & $\mathrm{p}$ \\
\hline \multicolumn{8}{|l|}{ (A) Tobit } \\
\hline Wild & 0.82 & 0.55 to 1.08 & 0.35 & 0.07 to 0.64 & 110 & 34.03 & $<0.001$ \\
\hline Cohort 1 & 2.65 & -4.70 to 10.01 & 1.83 & -10.62 to 6.96 & 6 & 1.07 & 0.301 \\
\hline Cohort 2 & 1.60 & 0.82 to 2.37 & -0.52 & -1.37 to 0.33 & 30 & 15.02 & $<0.001$ \\
\hline Cohort 3 & 0.89 & 0.36 to 1.42 & 0.33 & -0.23 to 0.87 & 25 & 11.88 & $<0.001$ \\
\hline Cohort 4 & 0.50 & -0.07 to 1.07 & 0.68 & 0.06 to 1.29 & 30 & 2.99 & 0.084 \\
\hline Cohort 5 & 1.03 & 0.09 to 1.97 & 0.15 & -0.81 to 1.11 & 19 & 4.64 & 0.031 \\
\hline Reared & 0.80 & 0.62 to 0.98 & 0.29 & 0.11 to 0.48 & 152 & 65.69 & $<0.001$ \\
\hline Batch 2 & 0.90 & 0.69 to 1.10 & 0.16 & -0.05 to 0.36 & 96 & & \\
\hline \multicolumn{8}{|c|}{ (B) Least-squares } \\
\hline Batch 1 & 0.80 & -0.18 to 1.77 & 0.32 & -0.75 to 1.39 & 26 & 0.107 & 0.104 \\
\hline Batch 3 & 1.93 & 1.79 to 2.07 & -0.75 & -0.86 to -0.63 & 115 & 0.872 & $<0.001$ \\
\hline Batch 4 & 1.13 & 0.79 to 1.47 & -0.07 & -0.39 to 0.24 & 36 & 0.570 & $<0.001$ \\
\hline Batch 5 & 2.00 & 1.59 to 2.41 & -0.69 & -0.95 to -0.43 & 40 & 0.717 & $<0.001$ \\
\hline Batch 6 & 1.86 & 1.32 to 2.41 & -0.66 & -1.02 to -0.31 & 29 & 0.646 & $<0.001$ \\
\hline
\end{tabular}

The transition to inertial environment, in red drum, is considered to take place at $\operatorname{Re}>1300$ (Sarkisian 2005). Pre-settlement individuals, $<7 \mathrm{~mm}$ TL, were clearly swimming in a viscous hydrodynamic environment $(\mathrm{Re}<600)$, while post-settlement individuals, $>11 \mathrm{~mm} \mathrm{TL}$, swam in an inertial hydrodynamic environment.

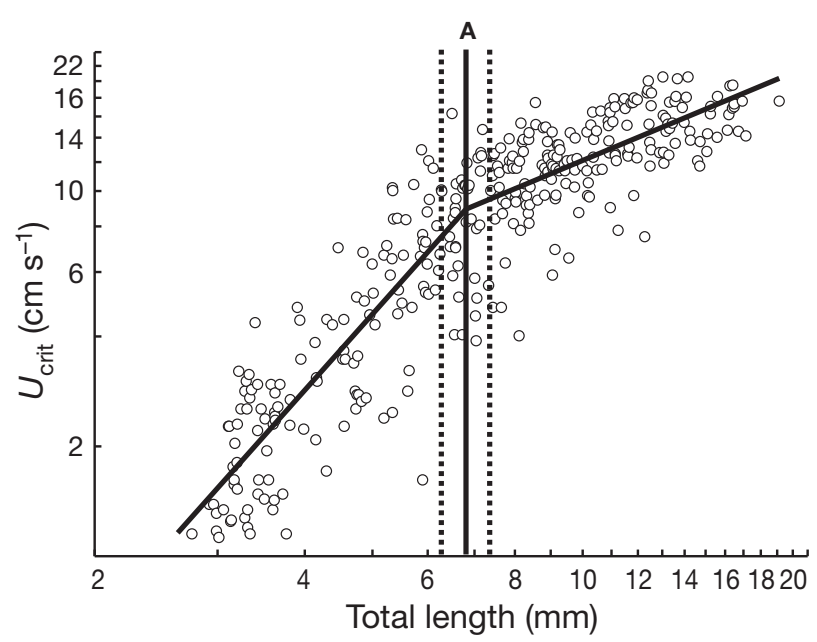

Fig. 4. Sciaenops ocellatus. Ontogeny of critical swimming speed for reared red drum larvae. The continuous line is a piecewise regression fitted to the data. Line A represents the breakpoint estimated by the piecewise regression $(6.9 \mathrm{~mm}$ total length [TL]), and the dashed lines represent the 95\% confidence interval for the breakpoint. Piecewise regression equation is: $U_{\text {crit }}=-0.83+2.14 \times \log \mathrm{TL}-1.36 \times(\log \mathrm{TL}-0.84) \times$ $(\log \mathrm{TL}>0.84)$

\section{DISCUSSION}

In red drum Sciaenops ocellatus larvae, critical swimming speeds of wild and reared larvae increase with ontogeny (size) and there is substantial variation at any given size, as found in other species (Fisher et al. 2000, 2005, Clark et al. 2005, Leis et al. 2007). Size was a better predictor of $U_{\text {crit }}$ than age when age was known (reared larvae). This has already been noted in recent studies on the ontogeny of larval fish behaviour (e.g. Clark et al. 2005, Leis et al. 2007), and it is not surprising, since 'a given ontogenetic state is usually reached at a uniform size for a species, regardless of how long it takes to achieve it' (Fuiman \& Higgs 1997, p. 238).

The ontogenetic increase in critical swimming speed occurs in 2 phases, and this sharp change in the trajectory of swimming performance coincides with important changes in ecology, morphology, and hydrodynamics. There is an early phase of more rapid improvement that changes to a later phase of slower improvement when larvae attain $6.9 \mathrm{~mm} \mathrm{TL}$, which is approximately the size at which red drum leave the water column and settle into seagrass beds (Rooker et al. 1998). Thus, swimming ability increases more rapidly during the pelagic (pre-settlement) stage than during the post-settlement stage. The period when larvae are $<6.9 \mathrm{~mm}$ TL is also characterized by radical changes in body shape and structure. Specifically, growth profiles showed that the head and caudal regions grow faster than the other parts of the

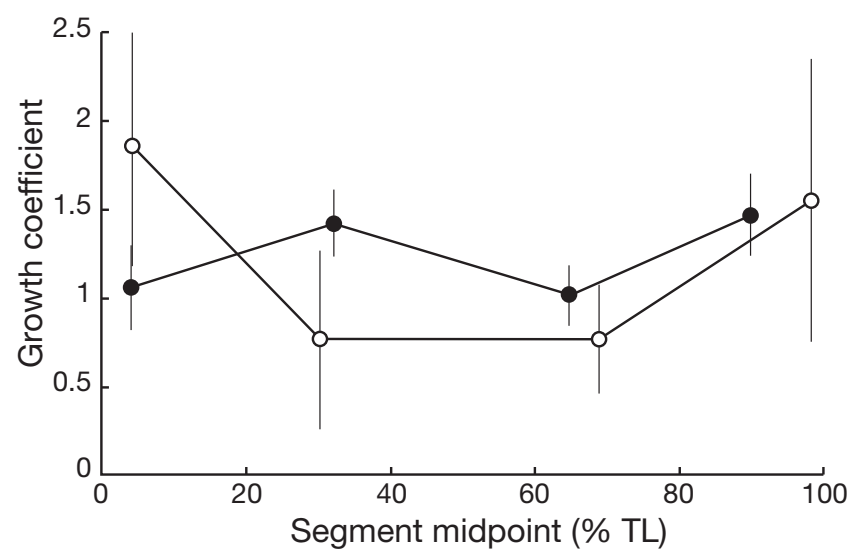

Fig. 5. Sciaenops ocellatus. Growth profile for longitudinally measured body segments of red drum larvae (as illustrated in Fig. 1). O: pre-settlement larvae; @: post-settlement larvae. TL: total length 
body at these smaller sizes. Finally, the critical swimming speed and size of larvae at the breakpoint between the 2 phases yield $\mathrm{Re} \approx 650$, which is the upper limit of the viscous hydrodynamic regime (Sarkisian 2005).

Previous studies have matched changes in swimming performance to developmental or ecological transitions, but the pattern of changes is not consistent across species. For shorthorn sculpin Myoxocephalus scorpius, Guan et al. (2008) found that critical swimming speed improved steadily through pelagic stages until metamorphosis, after which improvements became slower. These authors suggested that this decrease was due to a habitat shift associated with settlement. In contrast, Fisher et al. (2000) found that the swimming ability of coral reef fish larvae increased more slowly in the early life stages and faster in later stages. Clark et al. (2005) found that until notochord flexion was complete, both speed and endurance of 4 species of temperate marine fishes (in the families Sciaenidae, Sparidae, Percichthyidae) were limited, and swimming performance improved markedly thereafter.

Accentuated growth of the head and tail during the larval period is a characteristic of many species (Fuiman 1983, van Snik et al. 1997, Gisbert 1999). The aforementioned researchers have surmised that some of these morphological changes might have important locomotor consequences. Our assessment of relative growth and critical swimming speed provide empirical support to this claim.

Hydrodynamic conditions, as defined by fish size and swimming speed, can have a major influence on the energetic cost of swimming (Muller \& Videler 1996, Hunt von Herbing 2002). Small, slowly swimming larvae swim under conditions that are dominated by viscous forces when Re $<600$ (Fuiman \& Batty 1997, Sarkisian 2005) and move to inertia-dominated swimming when $\operatorname{Re}>1300$ (Sarkisian 2005). At the breakpoint between the 2 phases of ontogenetic increase in critical swimming speed, red drum larvae attain $\mathrm{Re}=640$. Under these conditions, they enter the intermediate hydrodynamic regime and begin to escape the energetic burden of the viscous hydrodynamic regime at the same time that highly allometric growth produces a body shape that is suited to efficient locomotion in an inertial hydrodynamic environment.

Temperate species are considered to be poorer swimmers than tropical species (Stobutzki \& Bellwood 1997). This may be due, in part, to differences in water temperature. Temperature influences both the physiology of fish larvae and the physics of the hydrodynamic environment in which larvae are swimming (Fuiman \& Batty 1997). Differences in performance may also be attributed to different methodologies. Some studies of swimming performance focus on routine (unforced) laboratory swimming (e.g. Fuiman et al. 1999, Fisher \& Bellwood 2003), others on swimming endurance (e.g. Dudley et al. 2000, Fisher \& Wilson 2004), some on swimming in the sea (Leis \& Carson-Ewart 1997), and others on critical swimming speeds (Fisher 2005, Fisher et al. 2005). Moreover, studies on reef fishes have concentrated on wild late-stage larvae (Stobutzki \& Bellwood 1997, Fisher \& Wilson 2004, Fisher et al. 2005), while studies on non-reef species have used laboratory-reared larvae at earlier developmental stages (Blaxter 1986, Miller et al. 1988). Other than these possibilities, variation can result from taxonomic and morphological differences (Leis \& Carson-Ewart 1997, Stobutzki 1998, Dudley et al. 2000). Most studies compare temperate clupeiform, gadiform, or pleuronectiform larvae (Blaxter 1986, Miller et al. 1988) with tropical perciform larvae (Fisher et al. 2000, 2005, Leis \& Fisher 2006). For this reason, comparisons of swimming speed among taxa should take into account phylogeny, methodology, and developmental state. It only makes sense to compare our results to other studies of $U_{\text {crit }}$ measured on perciform species within the same size range.

When comparing critical swimming speeds of settlement-stage red drum larvae (9.7 to $22.2 \mathrm{~cm} \mathrm{~s}^{-1}$ ) with the $U_{\text {crit }}$ for settlement-stage larvae of reef fishes (11.3 to $61.5 \mathrm{~cm} \mathrm{~s}^{-1}$; Leis \& Fisher 2006), we found that red drum swimming capabilities are within the range of those for reef fishes, although below the mean $(36 \mathrm{~cm}$ $\mathrm{s}^{-1}$ ). Dudley et al. (2000) also reported that when tropical and temperate species of similar taxonomic groups are compared, differences in swimming performance were small.

At the family level, we found only 2 other studies of behavioural ontogeny in a sciaenid, the mulloway Argyrosomus japonicus (Clark et al. 2005, Leis et al. 2006a). Maximum $U_{\text {crit }}$ for this species was $16.6 \mathrm{~cm} \mathrm{~s}^{-1}$, at $10 \mathrm{~mm}$ standard length (SL) (Clark et al. 2005), and in situ maximum speed was $8.4 \mathrm{~cm} \mathrm{~s}^{-1}$ at $11.4 \mathrm{~mm} \mathrm{SL}$ (Leis et al. 2006a). Thus, the larvae observed in situ were swimming much more slowly than their maximum capability $\left(U_{\text {crit }}\right)$, as expected (Fisher \& Bellwood 2002). When comparing maximum swimming performance of these 2 sciaenids, we conclude that at the same length (no information on ontogenetic state of $A$. japonicus is available), Sciaenops ocellatus swam $34 \%$ faster than A. japonicus (22.2 vs. $16.6 \mathrm{~cm} \mathrm{~s}^{-1}$ ). Temperature may not explain these differences, since both species were tested in a similar temperature range: S. ocellatus at 24 to $26^{\circ} \mathrm{C}$ and A. japonicus at 22 to $24^{\circ} \mathrm{C}$. Thus, these comparisons of taxonomically and ecologically similar species suggest that the relationship between swimming performance and size varies among species. 
What is the ecological importance of swimming abilities for estuarine species? Tidal currents can be very strong in estuarine inlets. Specifically, there are strong currents near the Lydia Ann Channel, where collections of red drum larvae were made, and the larvae are probably at a great risk of being swept away during ebb tide if they leave the shallow seagrass beds (Brown et al. 2005). During the sampling period, currents at the channel varied between 5 and $100 \mathrm{~cm} \mathrm{~s}^{-1}$, with an average speed of $35 \mathrm{~cm} \mathrm{~s}^{-1}$. Red drum larvae are unable to swim against this average speed; however, currents become slower as the water enters shallow areas, and one would expect that larvae use their strong swimming abilities to respond rapidly to high current flows in order to remain in the settlement habitat. Moreover, swimming abilities may also be needed to migrate further into the estuary. Rooker et al. (1998) suggested that post-settlement migration occurs in red drum, contrary to the 'settle and stay' hypothesis (Bell $\&$ Westoby 1986). Post-settlement transport can occur as a result of advection or behaviour (Jenkins et al. 1997, 1999). Brown et al. (2005) used a numerical circulation model coupled with a particle transport model to examine the role of physical transport in the spatial distribution of settled red drum larvae in the Aransas Pass region and found that physical processes can explain substantial retention of particles in the absence of behaviour in some areas, but not in others. The settlement sites in which the model reproduces temporal patterns in larval settlement are located closest to the gulf, while the sites in which the model performs the poorest are located further from the inlet, in regions with an indirect connection to the gulf.

A study in Australia also found that a particle transport model explained the larval settlement at a site closest to the entrance of the bay, but not at the site furthest from the entrance (Jenkins et al. 1997). The authors suggested that differences in the performance of the model may be attributed to the hydrodynamic model itself, or to the increasing importance of larval behaviour at sites located further from the centre of the estuary/bay. Bradbury et al. (2003) hypothesized that larvae reach a critical size at which active swimming overrides advection as the dominant factor in determining spatial patterns. These authors performed multiple ichthyoplankton surveys in Placentia Bay, Newfoundland, and found that the changes in spatial distribution patterns during the egg and early larval periods clearly indicated the importance of advection. However, the distribution of larger larvae of the most abundant species in the area (cod, capelin, and cunner) indicated these are increasingly capable of regulating their distributions (Bradbury et al. 2003), probably due to their strong swimming abilities (Williams et al. 1996).
It is frequently assumed that swimming performance of reared larvae is inferior to that of wild larvae (e.g. Blaxter 1975), although few direct comparisons have been made (e.g. Smith \& Fuiman 2004). Using reared larvae may not provide realistic results if their performance in the laboratory is poorer than that of wild larvae. Our study demonstrated that reared and wild larvae did not differ in swimming performance (measured as $U_{\text {crit }}$ ), suggesting that $U_{\text {crit }}$ measured in laboratory-reared fish may accurately reflect swimming abilities of wild red drum. However, this can only be concluded for post-settlement larvae, since we did not catch wild larvae < 8.25 mm TL. Smith \& Fuiman (2004) found significant differences between reared and wild red drum larvae in routine speed at some developmental stages, but not all. They did not measure critical swimming speed.

It is important to note that $U_{\text {crit }}$ is a laboratory measure of forced performance, and it is unlikely that larvae are able to sustain maximum critical speeds in the wild for extended periods. An approach that could clarify the actual behaviour of red drum larvae in the wild would be to follow larvae in situ, as has been done by Trnski (2002) and Leis et al. (2006a,b). There was a strong correlation between $U_{\text {crit }}$ and in situ speed for 3 temperate species and 11 tropical species (Leis \& Fisher 2006, Leis et al. 2006a), whereby in situ speeds averaged $50 \%$ of $U_{\text {crit }}$ (Leis \& Fisher 2006). This relationship makes it possible to estimate swimming speeds of larvae in the ocean from an easy and convenient laboratory measure, such as $U_{\text {crit }}$ (Leis \& Fisher 2006). It would be useful to confirm this relationship for red drum, but it must be recognized that the waters occupied by red drum larvae are much more turbid than those in which in situ measurements have been made and that it might not be possible to achieve the same success.

Additional studies on the behaviour of early life histories of fishes, and in particular on swimming abilities, are essential to our knowledge. Only a more realistic view of swimming behaviour will help us to understand and predict the dispersal and retention patterns of species in coastal zones.

Acknowledgements. We thank C. M. Pratt and J. Williams for assistance with field work. Thanks also to the editor and 5 anonymous reviewers for very constructive comments and suggestions on the manuscript. This work was supported by a PhD grant to A.M.F. (SFRH/BD/21742/2005) and through the Pluriannual Program (R \& D Unit 331/94), financed by Fundação para a Ciência e a Tecnologia. Partial support was provided by the (US) National Science Foundation under Grant No. (OCE 0425241) to L.A.F. This is Contribution Number 1507 of the University of Texas Marine Science Institute. 


\section{LITERATURE CITED}

Amemiya T (1984) Tobit models: a survey. J Econom 24:3-61

Bell JD, Westoby M (1986) Variation in seagrass height and density over a wide spatial scale: effects on fish and decapods. J Exp Mar Biol Ecol 104:249-274

Blaxter JHS (1975) Reared and wild fish - How do they compare? In: Persoone G, Jaspers E (eds) Proc 10th Eur Mar Biol Symp, Vol 1. Universa Press, Wetteren, p 11-16

Blaxter JHS (1986) Development of sense organs and behaviour of teleost larvae with special reference to feeding and predator avoidance. Trans Am Fish Soc 115:98-114

Bradbury IR, Snelgrove PVR, Pepin P (2003) Passive and active behavioural contributions to patchiness and spatial pattern during the early life history of marine fishes. Mar Ecol Prog Ser 257:233-245

Brett JR (1964) The respiratory metabolism and swimming performance of young sockeye salmon. J Fish Res Board Can 21:1183-1226

Brown C, Laland K (2001) Social learning and life skills training for hatchery reared fish. J Fish Biol 59:471-493

> Brown CA, Jackson GA, Holt SA, Holt GJ (2005) Spatial and temporal patterns in modeled particle transport to estuarine habitat with comparisons to larval fish settlement patterns. Estuar Coast Shelf Sci 64:33-46

Clark DL, Leis JM, Hay AC, Trnski T (2005) Swimming ontogeny of larvae of four temperate marine fishes. Mar Ecol Prog Ser 292:287-300

Danilowicz BS (1996) Choice of coral species by naïve and field-caught damselfish. Copeia 1996:735-739

Doherty PJ (1987) Light-traps: selective but useful devices for quantifying the distributions and abundances of larval fishes. Bull Mar Sci 41:423-431

Dudley B, Tolimieri N, Montgomery J (2000) Swimming ability of the larvae of some reef fishes from New Zealand waters. Mar Freshw Res 51:783-787

> Dufour V, Galzin R (1993) Colonization patterns of reef fish larvae to the lagoon at Moorea Island, French Polynesia. Mar Ecol Prog Ser 102:143-152

Fisher R (2005) Swimming speeds of larval coral reef fishes: impacts on self-recruitment and dispersal. Mar Ecol Prog Ser 285:223-232

Fisher R, Bellwood DR (2002) A light trap design for stratumspecific sampling of reef fish larvae. J Exp Mar Biol Ecol 269:27-37

Fisher R, Bellwood DR (2003) Undisturbed swimming behaviour and nocturnal activity of coral reef fish larvae. Mar Ecol Prog Ser 263:177-188

Fisher R, Wilson SK (2004) Maximum sustainable swimming speeds of late-stage larvae of nine species of reef fishes. J Exp Mar Biol Ecol 312:171-186

> Fisher R, Bellwood DR, Job SD (2000) Development of swimming abilities in reef fish larvae. Mar Ecol Prog Ser 202: 163-173

Fisher R, Leis JM, Clark DL, Wilson SK (2005) Critical swimming speeds of late-stage coral reef fish larvae: variation within species, among species and between locations. Mar Biol 147:1201-1212

Forward RB Jr, Tankersley RA, Reinsela KA (1998) Selective tidal stream transport of spot (Leistomus xanthurus Lacepede) and pinfish (Lagodon rhomboides [Linnaeus]) larvae: contribution of circatidal rhythms in activity. J Exp Mar Biol Ecol 226:19-32

Forward RB Jr, Reinsel KA, Peters DS, Tankersley RA and others (1999) Transport of fish larvae through a tidal inlet. Fish Oceanogr 8:153-172

Fuiman LA (1983) Growth gradients in fish larvae. J Fish Biol 23:117-123
Fuiman LA, Batty RS (1997) What a drag it is getting cold: partitioning the physical and physiological effects of temperature on fish swimming. J Exp Biol 200:1745-1755

Fuiman LA, Higgs DM (1997) Ontogeny, growth and the recruitment process. In: Chambers RC, Trippel EA (eds) Early life history and recruitment in fish populations. Chapman \& Hall, London, p 225-249

Fuiman LA, Ottey DR (1993) Temperature effects on spontaneous behavior of larval and juvenile red drum Sciaenops ocellatus, and implications for foraging. Fish Bull (Wash DC) 91:23-35

Fuiman LA, Smith ME, Malley VN (1999) Ontogeny of routine swimming speed and startle responses in red drum, with a comparison of responses to acoustic and visual stimuli. J Fish Biol 55:215-226

Gisbert E (1999) Early development and allometric growth patterns in Siberian sturgeon and their ecological significance. J Fish Biol 54:852-862

> Guan L, Snelgrove PVR, Gamperl AK (2008) Ontogentic changes in the critical swimming speed of Gadus morhua (Atlantic cod) and Myoxocephalus scorpius (shorthorn sculpin) larvae and the role of temperature. J Exp Mar Biol Ecol 360:31-38

Holt SA, Holt GJ, Arnold CR (1989) Tidal stream transport of larval fishes into non-stratified estuaries. Rapp P-V Réun Cons Int Explor Mer 191:100-104

Hunt von Herbing I (2002) Effects of temperature on larval fish swimming performance: the importance of physics to physiology. J Fish Biol 61:865-876

Jenkins GP, Welsford D (2002) The swimming abilities of recently settled post-larvae of Sillaginodes punctata. J Fish Biol 60:1043-1050

Jenkins GP, Black KP, Wheatley MJ, Hatton DN (1997) Temporal and spatial variability in recruitment of a temperate, seagrass-associated fish is largely determined by physical processes in the pre- and post-settlement phases. Mar Ecol Prog Ser 148:23-35

Jenkins GP, Black KP, Keough MJ (1999) The role of passive transport and the influence of vertical migration on the pre-settlement distribution of a temperate, demersal fish: numerical model predictions compared with field sampling. Mar Ecol Prog Ser 184:259-271

> Leis JM (2006) Are larvae of demersal fishes plankton or nekton? Adv Mar Biol 51:57-141

> Leis JM, Carson-Ewart BM (1997) In situ swimming speeds of the late pelagic larvae of some Indo-Pacific coral-reef fishes. Mar Ecol Prog Ser 159:165-174

> Leis JM, Carson-Ewart BM (2003) Orientation of pelagic larvae of coral-reef fishes in the ocean. Mar Ecol Prog Ser 252:239-253

Leis JM, Fisher R (2006) Swimming speed of settlementstage reef-fish larvae measured in the laboratory and in the field: a comparison of critical speed and in situ speed. In: Suzuki Y, Nakamori T, Hidaka M, Kayanne H and others (eds) Proc 10th Int Coral Reef Symp. Okinawa 2004. Japanese Coral Reef Society, Tokyo, p 438-445

Leis JM, Stobutzki IC (1999) Swimming performance of late pelagic larvae of coral-reef fishes: in situ and laboratorybased measurements. In: Séret B, Sire JY (eds) Proc 5th Indo-Pacific Fish Conf, Nouméa, 1997. Société Française d'Ichtyologie et Institut de Recherche pour le Développement, Paris, p 575-583

Leis JM, Hugh PA, Reader SE (1996) What the pelagic stages of coral reef fishes are doing out in blue water: daytime field observations of larval behavioural capabilities. Mar Freshw Res 47:401-411

Leis JM, Hay AC, Trnski T (2006a) In situ ontogeny of behav- 
iour in pelagic larvae of three temperate, marine, demersal fishes. Mar Biol 148:655-669

Leis JM, Hay AC, Clark DA, Chen IS, Shao KT (2006b) Behavioral ontogeny in larvae and early juveniles of the giant trevally, Caranx ignobilis (Pisces: Carangidae). Fish Bull (Wash DC) 104:401-414

Leis JM, Hay AC, Lockett MM, Chen JP, Fang LS (2007) Ontogeny of swimming speed in larvae of pelagic-spawning, tropical, marine fishes. Mar Ecol Prog Ser 349:255-267

Miller TJ, Crowder LB, Rice JA, Marschall EA (1988) Larval size and recruitment mechanisms in fishes: toward a conceptual framework. Can J Fish Aquat Sci 45:1657-1688

Montgomery JC, Tolimieri N, Haine OS (2001) Active habitat selection by pre-settlement reef fishes. Fish Fish 2:261-277

Muller UK, Videler JJ (1996) Inertia as a 'safe harbour': Do fish larvae increase length growth to escape viscous drag? Rev Fish Biol Fish 6:353-360

Olla BL, Davis MW, Ryer CH (1998) Understanding how the hatchery environment represses or promotes the development of behavioral survival skills. Bull Mar Sci 62:531-550

Peters K, McMichael Jr RH (1987) Early life history of the red drum, Sciaenops ocellatus (Pisces: Sciaenidae), in Tampa Bay, Florida. Estuaries 10:92-107

Plaut I (2001) Critical swimming speed: its ecological relevance. Comp Biochem Physiol Comp Physiol 131:41-50

Rooker JR, Holt SA, Soto MA, Holt GJ (1998) Postsettlement patterns of habitat use by sciaenid fishes in subtropical seagrass meadows. Estuaries 21:318-327

Sarkisian B (2005) From viscous to inertial forces: defining the limits of hydrodynamic regimes for larval fishes. MS thesis, University of Texas at Austin, Austin, TX

Smith ME, Fuiman LA (2004) Behavioral performance of wildcaught and laboratory-reared red drum Sciaenops ocellatus (Linnaeus) larvae. J Exp Mar Biol Ecol 302:17-33

Editorial responsibility: Jon Hare,

Narragansett, Rhode Island, USA
Stobutzki IC (1998) Interspecific variation in sustained swimming ability of late pelagic stage reef fish from two families (Pomacentridae and Chaetodontidae). Coral Reefs 17: 111-119

Stobutzki IC, Bellwood DR (1994) An analysis of the sustained swimming abilities of pre- and post-settlement coral reef fishes. J Exp Mar Biol Ecol 175:275-286

Stobutzki IC, Bellwood DR (1997) Sustained swimming abilities of the late pelagic stages of coral reef fishes. Mar Ecol Prog Ser 149:35-41

Stunz GW, Minello TJ, Levin PS (2002) Growth of newly settled red drum Sciaenops ocellatus in different estuarine habitat types. Mar Ecol Prog Ser 238:227-236

Tobin J (1958) Estimation for relationships with limited dependent variables. Econometrica 26:24-36

> Trnski T (2002) Behaviour of settlement-stage larvae of fishes with an estuarine juvenile phase: in situ observations in a warm-temperate estuary. Mar Ecol Prog Ser 242:205-214

> van Snik GMJ, van den Boogaart JGM, Osse JWM (1997) Larval growth patterns in Cyprinus carpio and Clarias gariepinus with attention to the finfold. J Fish Biol 50: 1339-1352

von Westernhagen H, Rosenthal H (1979) Laboratory and insitu studies on larval development and swimming performance of Pacific herring, Clupea harengus pallasi. Helgol Mar Res 32:539-549

Webb PW, Weihs D (1986) Functional locomotor morphology of early life history stages of fishes. Trans Am Fish Soc 115: 115-127

Williams PJ, Brown JA, Gotceitas V, Pepin P (1996) Developmental changes in escape response performance of five species of marine larval fish. Can J Fish Aquat Sci 53: $1246-1253$

Submitted: May 19, 2008; Accepted: March 18, 2009 Proofs received from author(s): May 16, 2009 